\title{
Factors Associated with Follow-Up of Children Exposed to Mother-to-Child Transmission of HIV: A Historical Cohort Study Form 2000 to 2017, in Porto Alegre, Brazil.
}

Karen da Silva Calvo

Universidade Federal do Rio Grande do Sul

Daniela Riva Knauth

Universidade Federal do Rio Grande do Sul

Bruna Hentges

Universidade Federal do Rio Grande do Sul

Andrea Fachel Leal

Universidade Federal do Rio Grande do Sul

Mariana Alberto da Silva

Universidade Federal do Rio Grande do Sul

Danielle Lodi Silva

Universidade Federal do Rio Grande do Sul

Samantha Correa Vasques

Universidade Federal do Rio Grande do Sul

Letícia Hamester

Universidade Federal do Rio Grande do Sul

Daila Alena Raenck da Silva

Universidade Federal do Rio Grande do Sul

Fernanda Vaz Dorneles

General Directorate of Health Surveillance

Fernando Santana Fraga

Universidade Federal do Rio Grande do Sul

Paulo Ricardo Bobek

Universidade Federal do Rio Grande do Sul

Luciana Barcellos Teixeira ( $\square$ Luciana.bteixeira@gmail.com )

Universidade Federal do Rio Grande do Sul

Research Article 
Keywords: HIV/AIDS, Children exposed to HIV, Loss to follow-up, Mother-to-child transmission of HIV

Posted Date: September 20th, 2021

DOI: https://doi.org/10.21203/rs.3.rs-764111/v1

License: (c) (1) This work is licensed under a Creative Commons Attribution 4.0 International License. Read Full License 


\section{Abstract}

Background: There are many inequalities in terms of prevention and treatment for pregnant women with HIV and exposed children in low and middle income countries. The Brazilian protocol for prenatal care includes rapid diagnostic testing for HIV, compulsory notification, and monitoring by the epidemiological surveillance of children exposed to HIV until 18 months after delivery. The case is closed after HIV serology results are obtained. Loss to follow-up is defined as a child who was not located at the end of the case, and, therefore, did not have a laboratory diagnosis. Loss to follow-up is a current problem and has been documented in other countries. This study analyzed the incidence of loss to follow-up of children exposed to HIV and the sociodemographic, behavioral and health variables of associated pregnant women.

Methods: This historical cohort study included information on pregnant women living with HIV and the outcome of the child's exposure to HIV. The association between predictors and the child's outcome as a loss to follow-up was investigated using the Poisson Regression model. Relative Risk calculations were performed. The significance level of $5 \%$ was adopted for variables in the adjusted model.

Results: Between 2000 and 2017, of 6,836 children exposed to HIV, 1,763 (25.8\%) were classified as loss to follow-up. The factors associated were: maternal age of up to 22 years (aRR 1.25, 95\% Cl: 1.09-1.43), the mother's self-declared race/color being black or mixed (aRR 1.13,95\% Cl: 1.03-1.25), up to three years of schooling (aRR 1.45, 95\% Cl: 1.26-1.67), between four and seven years of schooling (aRR 1.14, 95\% Cl: 1.02-1.28), intravenous drug use (aRR 1.29, 95\% Cl: 1.12-1.50), and HIV diagnosis during prenatal care or at delivery (aRR 1.37, 95\% Cl: 1.24-1.52).

Conclusion: Variables related to the individual, social and programmatic vulnerability of pregnant women were evidenced.

\section{Background}

HIV in children can be avoided through prevention and treatment for pregnant women with HIV and exposed children. It is estimated that 1.4 million women living with HIV become pregnant each year [1]. The increase in the rate of pregnant women with HIV who had access to the use of antiretroviral therapy (ART) in recent years - from $51 \%$ in 2010 to $80 \%$ in 2017 - was one of the key factors in preventing new infections in children worldwide [2]. This percentage, however, varies according to the weaknesses related to prenatal and postnatal care of health systems, especially in developing countries [3-5].

In Brazil, in the period from 2000 to June 2020, 134,328 HIV-infected pregnant women were notified [6]. As for the rate of HIV detection in pregnant women, there was an increase of $21.7 \%$ over a ten-year period: in 2009, 2.3 cases/thousand live births were registered, and, in 2019, this rate increased to 2.8 cases/thousand live births. Compared to other Brazilian state capitals, Porto Alegre, the location of this study, is the capital with the highest detection rate, with 17.6 cases/thousand live births recorded in 2019 , a rate six times higher than the national rate [6]. 
Reducing the number of children infected with HIV and offering $95 \%$ treatment coverage is among the 9595-95 goals that aim to prevent 5.9 million infections in children up to 15 years of age by 2030 [7]. Over the years, many actions have been documented in this area, especially in prenatal care, among which are the intensification of educational activities, the provision of rapid tests, the supply of antiretroviral therapy, and supplies of substitute inputs for breast-feeding [8-11]. The result of investment in the implementation of programs and actions showed that, between 2000 and 2018, the number of new infections in children decreased from over 400,000 to $160,000[1,12]$. Despite this, early diagnosis remains one of the main challenges [13-15]. The absence of a confirmatory test in children precludes the timely start of antiretroviral therapy (ART) $[12,16,17]$.

There are many inequalities in terms of prevention and treatment for pregnant women with HIV and exposed children in low and middle income countries [5, 17-20]. In Brazil, ART is universally distributed by the public health system. Therefore, an epidemiological surveillance system with complete information on children exposed to HIV would greatly increase the ability to target services to those that need them.

The Brazilian protocol for prenatal care includes rapid diagnostic testing for HIV, compulsory notification, and monitoring by the epidemiological surveillance of children exposed to HIV until 18 months after delivery [21]. The case is closed after HIV serology results are obtained. Loss to follow-up is defined as a child who was not located at the end of the case, and, therefore, did not have a laboratory diagnosis. Loss to follow-up is a current problem and has been documented in other countries [17, 22-25].

In the city of Porto Alegre, approximately 400 children exposed to HIV are monitored annually. Case closure as a loss to follow-up is not uncommon. Ignoring the serological status of exposed children makes it impossible to start early interventions, contributing to infant morbidity and mortality [1, 26-28]. This article aims to analyze the incidence of the loss to follow-up of children exposed to HIV. All sociodemographic and behavioral variables available in the National Surveillance System related to pregnant women living with HIV were investigated.

We believe that this analysis can contribute to the development of more systematic monitoring strategies, strengthening epidemiological surveillance in Porto Alegre, the Brazilian state capital with the highest rate of HIV detection in pregnant women.

\section{Methodology}

\section{Participants}

Pregnant women living with HIV and children exposed to HIV who were born between 2000 and 2017 were included. In the study scenario, the investigation of the child's exposure to HIV ends 24 months after birth. Children under 18 months of age are considered infected when their detectable plasma RNA levels are over 10,000 copies or when proviral DNA is detected in two samples collected at different times. HIVexposed children 18 months of age or older are considered infected when a serum sample is positive in a 
screening test or a confirmatory test for anti-HIV antibody testing, or in two rapid tests. The child is considered lost to follow-up at 24 months of follow-up without the completion of the laboratory diagnosis, when the case is closed [29]. The unavailability of information is usually due to the lack of health care for the child in health units, at an age in which children should get regular check-ups.

This historical cohort study included information on pregnant women living with HIV and the outcome of the child's exposure to HIV.

\section{Procedures and measures}

The epidemiological surveillance service is responsible for registering information of pregnant women living with HIV, as well as to monitor and update the health outcome of children exposed to HIV. In Brazil, such data are stored in a system called "Notifiable Diseases Information System" (SINAN), fed by compulsory notification. Sociodemographic (age, race/color and schooling), behavioral (lifetime injecting drug use), and health-related (time of HIV diagnosis, beginning of prenatal care, and use of ART during childbirth) information of pregnant women were all collected in the system in order to analyze possible associated factors. The outcome of the child's exposure was obtained using the same system.

The database made available by the epidemiological surveillance service included all children exposed to HIV notified in the city of Porto Alegre with their respective updated results. There is an active search for children classified as loss to follow-up, which is carried out by health professionals in the city. The searches aim to locate and test the child in order to close the case as HIV positive or negative.

The research data were collected by two trained researchers, during a six-month period in the year 2020, directly from SINAN. There were 928 cases with missing information on race/color. To look for this information, other information systems were accessed, such as the Laboratory Examination Control System (SISCEL), the Logistic Control System for Medicines (SICLOM), the electronic medical record of the primary care user (E-SUS) and the SUS User Registration System (CADSUS). Of this total, 217 cases still had missing information on race/color.

The sociodemographic data presented refer to pregnant women at the time they were notified of HIV by the health services. The study's outcome was the closure status of cases of children exposed to HIV. A child who underwent HIV testing was considered a completed case, regardless of positive or negative serology status. Children exposed to HIV who could not be located in the health care system for laboratory diagnosis at the time the case was closed were considered loss to follow-up.

In terms of the variables, schooling was categorized as "up to three" years of study (including women who never attended school), "between four and seven" years of study, and "eight years or more" years of study.

The information on the moment of HIV diagnosis for the pregnant woman was already grouped in the original data into two categories: (i) before prenatal care, or (ii) during prenatal care or at delivery. This was therefore used with these two categories in the statistical analysis. 
This study was approved by the Ethics and Research Committee of the Federal University of Rio Grande do Sul and by the Ethics and Research Committee of the Municipality of Porto Alegre.

\section{Statistical analysis}

Statistical analysis was performed using SPSS Software, version 22.0. Absolute numbers and frequencies were used for sample description. Comparisons were made either using the homogeneity of proportions test based on Pearson's or Fisher's chi-square statistics and standardized residuals. The level of significance adopted was $5 \%$.

The association between predictors and the child's outcome as a loss to follow-up was investigated using the Poisson Regression model. Relative Risk calculations were performed in unadjusted and adjusted models. The level of significance used was $p<0.20$ in the unadjusted model for insertion of variables in the adjusted model. The significance level of $5 \%$ was adopted for variables in the adjusted model. Pvalues of the models were derived from the Wald test.

\section{Results}

Between 2000 and 2017, 8,190 children exposed to mother-to-child transmission of HIV during pregnancy were notified. Of these, in 520 cases the pregnancy resulted in abortion, in 212 cases the children died within 24 months of follow-up, and in 622 cases moved to a different city where it was not possible to complete the follow-up. Thus, the total for this analysis was 6,836 cases. Of this number, 1,763 (25.8\%) children were classified as lost to follow-up.

Table 1 describes the sociodemographic and behavioral profile of pregnant women living with HIV. The proportions of mothers of children lost to follow-up differ across age categories $(p<0.001)$. The mothers of children classified as "lost to follow-up" are younger. Regarding race/color, there is a higher percentage of women declaring themselves to be black or mixed in the loss to follow-up group $(p=0.001)$. There is a significant difference in schooling between groups $(p<0.001)$. Pregnant women with up to three years of schooling were more frequent in the loss to follow-up group. Intravenous drug use was more prevalent in the loss to follow-up group $(\mathrm{p}=0.003)$. Among women who were HIV diagnosed during prenatal care or at delivery, $34.7 \%$ were lost to follow-up, while among those diagnosed before prenatal care, $24 \%$ resulted in loss to follow-up $(p<0.001)$. 
Table 1

Demographic, behavioral and health profile of pregnant women living with HIV notified to SINAN, in Porto Alegre, according to the outcome loss to follow-up, 2000-2017.

\section{Loss to follow-up}

\section{Characteristics}

Age range

Up to 22

$23-26$

$27-31$

32 or more

Race/Color

White

Black or mixed

Schooling

Up to three years

Between four and seven years

Eight years or more

\section{Partner with HIV}

Yes

No

Intravenous drug use

Yes

No

\section{HIV diagnosis}

During prenatal care or at delivery

Before prenatal care

Total

*Totals may differ due to the possibility of lack of response. **Proportion homogeneity test based on Fischer's Test or Pearson's chi-square statistic. ${ }^{1}$ Standardized residual $(=3.1) .{ }^{2}$ Standardized residual $(=2.2) .{ }^{3}$ Standardized residual $(=4.3) .{ }^{4}$ Standardized residual $(=2.6) .{ }^{5}$ Standardized residual $(=5.9)$.

\begin{tabular}{lll} 
Total (\%)* & Yes (\%)* & No (\%)* \\
\hline $1,952(28,6)$ & $574(29.4)^{1}$ & $1,378(70.6)$ \\
\hline $1,549(22.7)$ & $409(26.4)$ & $1140(73.6)$ \\
$1,691(24.8)$ & $398(23.5)$ & $1293(76.5)$ \\
$1,640(24)$ & $383(23.3)$ & $1258(76.7)$
\end{tabular}

0.001

3,798 (57.4) $\quad 917(24.1) \quad 2,881(75.9)$

$2,821(42.6) \quad 782(27.7)^{2} \quad 2,039(72.3)$

\begin{tabular}{lll}
$858(13.9)$ & $286(33.3)^{3}$ & $572(66.7)$ \\
\hline $3,062(49.7)$ & $796(26)$ & $2,266(74)$ \\
\hline $2,244(36.4)$ & $511(22.8)$ & $1,733(77.2)$
\end{tabular}

0.149

$3.148(73.3) \quad 790(25.1) \quad 2,358(74.9)$

$1,148(26.7) \quad 263(22.9) \quad 885(77.1)$

0.003

$500(8.4) \quad 154(30.8)^{4} \quad 346(69.2)$

$5,486(91.6) \quad 1,347(24.6) \quad 4,139(75.4)$

$<0.001$

\begin{tabular}{lll}
$4,045(72)$ & $970(24)$ & $3.075(76)$ \\
\hline $1,575(28)$ & $546(34.7)^{5}$ & $1,029(65.3)$ \\
\hline 6,836 & $1,763(25.8)$ & $5,073(74.2)$
\end{tabular}


Table 2 presents the results of the non-adjusted models and adjusted models. The following socioeconomic, behavioral and health factors of the studied mothers were associated with loss to followup in the final model: being up to 22 years of age (aRR 1.25; 95\% $\mathrm{Cl} 1.09-1.43)$; being self-declared as black or mixed (aRR 1.13; 95\% Cl 1.03-1.25); up to three years of study (aRR 1.45; 95\% Cl 1.26-1.67); from four to seven years of study (aRR 1.14; 95\% $\mathrm{Cl} 1.02-1.28$ ); intravenous drug use (aRR $1.29 ; 95 \% \mathrm{Cl}$ 1.12-1.50); and HIV diagnosis during prenatal care (aRR 1.37; 95\% Cl 1.24-1.52). 
Table 2

Factors associated with loss to follow-up of children exposed to HIV in Porto Alegre, 2000-2017.

\begin{tabular}{|c|c|c|c|c|c|c|}
\hline Characteristics & $\begin{array}{l}\text { Unadjusted } \\
\mathrm{RR}^{\star}\end{array}$ & $\mathrm{Cl} 95 \%$ & p & $\begin{array}{l}\text { Adjusted } \\
\mathrm{RR}^{\star \star}\end{array}$ & Cl 95\% & p \\
\hline Age range & & & $<.001$ & & & 0.003 \\
\hline Up to 22 & 1.26 & $\begin{array}{l}1.13- \\
1.41\end{array}$ & & 1.25 & $\begin{array}{l}1.09- \\
1.43\end{array}$ & \\
\hline $23-26$ & 1.13 & $\begin{array}{l}1.01- \\
1.28\end{array}$ & & 1.13 & $\begin{array}{l}0.97- \\
1.31\end{array}$ & \\
\hline $27-31$ & 1.01 & $\begin{array}{l}0.89- \\
1.14\end{array}$ & & 1.01 & $\begin{array}{l}0.87- \\
1.17\end{array}$ & \\
\hline 32 or more & 1 & & & 1 & & \\
\hline Race/Color & & & 0.001 & & & 0.013 \\
\hline White & 1 & - & & 1 & - & - \\
\hline Black or mixed & 1.15 & $\begin{array}{l}1.06- \\
1.25\end{array}$ & & 1.13 & $\begin{array}{l}1.03- \\
1.25\end{array}$ & \\
\hline Schooling & & & $<.001$ & & & $\begin{array}{l}< \\
0.001\end{array}$ \\
\hline Up to three years & 1.46 & $\begin{array}{l}1.30- \\
1.65\end{array}$ & & 1.45 & $\begin{array}{l}1.26- \\
1.67\end{array}$ & \\
\hline $\begin{array}{l}\text { Between four and seven } \\
\text { years }\end{array}$ & 1.14 & $\begin{array}{l}1.04- \\
1.26\end{array}$ & & 1.14 & $\begin{array}{l}1.02- \\
1.28\end{array}$ & \\
\hline Eight years or more & 1 & & & 1 & & \\
\hline \multicolumn{7}{|l|}{ Intravenous drug use } \\
\hline Yes & 1.25 & $\begin{array}{l}1.09- \\
1.44\end{array}$ & 0.001 & 1.29 & $\begin{array}{l}1.12- \\
1.50\end{array}$ & 0.001 \\
\hline No & 1 & - & - & 1 & - & - \\
\hline \multicolumn{7}{|l|}{ HIV diagnosis } \\
\hline $\begin{array}{l}\text { During prenatal care or at } \\
\text { delivery }\end{array}$ & 1.45 & $\begin{array}{l}1.32- \\
1.58\end{array}$ & $<.001$ & 1.37 & $\begin{array}{l}1.24- \\
1.52\end{array}$ & $\dot{0} 001$ \\
\hline Before prenatal care & 1 & - & - & 1 & - & - \\
\hline
\end{tabular}

\section{Discussion}


Our data indicate that the epidemiological surveillance system in the city of Porto Alegre is unaware of the diagnosis of about a quarter of the children exposed to HIV. This finding shows the number of children without diagnosis at a critical moment in life their lives. The absence of data also implies possible distortions in the rate of mother-to-child transmission of HIV, as many children considered to be lost to follow-up may have had a positive result. The lack of information on the serology status of exposed children within the health care system can therefore impact the planning and implementation of policies aimed at HIV prevention and care [17, 30, 31].

This is a problem that affects not only Brazil, but also other countries that often have higher rates of loss to follow-up of children exposed to HIV [14,20,32]. In a meta-analysis, the estimated loss to follow-up of children exposed to HIV in 11 Sub-Saharan African countries was $33.9 \%$ (95\% Cl $27.6 \%-41.5 \%$ ) in the three-month postpartum period. This study showed that there was little research in Sub-Saharan Africa that included a longer follow-up period. However, two studies in South Africa followed children for 12 months, with loss to follow-up of $85.1 \%$ and $50.2 \%$. Other surveillance services that investigated children exposed to HIV for 18 months showed that the loss to follow-up ranged from 20.8 to $66.1 \%$ [33]. In a recent study that analyzed the follow-up of children exposed to HIV at a referral hospital in Uganda, the percentage of loss to follow-up was $48 \%$ in 18 months [3].

From a Brazilian public policy perspective, these results indicate the difficulty of that primary care services have in identifying, linking, and retaining care for children exposed to HIV, problems also seen in other studies [9, 22, 25, 34-37]. In Brazil, primary care services are responsible for monitoring all newborns within their geographic areas of coverage [38]. In a review of access to services to prevent mother-to-child transmission of HIV, Hiarlaithe et al. (2014) identified the following access barriers: cost of traveling to the health service, secrecy in relation to diagnosis, the stigma surrounding HIV, and relationship with the partner [39]. In a study conducted in Ethiopia, it was found that the proportion of pregnant women who have comprehensive knowledge about preventing mother-to-child transmission of HIV was low [40]. Difficulty of access and level of knowledge were not investigated in this study, however, and these issues may be related to loss to follow-up.

Our data indicate that the loss to follow-up of children exposed to HIV is associated with the different dimensions of vulnerability of pregnant women with HIV [41]. In the individual dimension, there is intravenous drug use; in the social dimension, being under 26 years of age, being black or mixed and having up to seven years of study; and in the programmatic dimension, the diagnosis of HIV during prenatal care or at delivery. This last result indicates that women with HIV enter the health service later $[42,43]$.

In the individual dimension, drug use appears to be associated with lower adherence to care for the prevention and treatment of HIV [44, 45]. In addition to the effects of the substances used, marginalization and stigma related to drug use and HIV itself are factors that interfere with access to and adherence to treatment [46]. In this sense, we emphasize that harm reduction strategies [47] could 
improve care, avoiding loss of follow-up. Care and social support interventions for drug users have shown better standards of care and adherence to drugs $[48,49]$.

In the social dimension, children whose mothers were up to 22 years old were at an excess risk of $25 \%$, when compared to children of mothers over 32. Age may be interconnected with other factors, such as low socioeconomic status, lower education and knowledge about HIV [40]. Regarding race/color, black or mixed women had a relative risk $13 \%$ higher to have children lost to follow-up. These data can be contextualized from the perspective of institutional racism [50,51], which accentuates the inequality of access to health which has already been observed in the issue of race/color in Brazil in relation to HIV [6]. Regarding schooling, women with up to three years of schooling had a $45 \%$ excess risk of having children lost to follow-up. In the discussion on social vulnerability, education is an important element, as it represents possibilities for entering the labor market and has also been interpreted as an income proxy [52]. In the scenario in which this study was carried out, with cultural issues intertwined with the definition of roles associated with gender, we understand that younger women with less schooling may be financially dependent on their sexual partners, which would make the child more vulnerable to being lost to follow-up.

In the programmatic dimension women who were diagnosed with HIV during the prenatal period or at delivery had an excess risk of $37 \%$ to have a child classified as loss to follow-up. In our study, most pregnant women were already aware of the HIV diagnosis before prenatal care (72\%); however, the percentage of pregnant women who received the diagnosis in prenatal care or at delivery was still high, and was even greater in the loss to follow-up group (34.7\% versus $24 \%$ ). Barriers to HIV testing in primary care have been documented [53-55], so the possibility of HIV testing during prenatal care appears to be an opportunity to improve care.

This would be an alert for health professionals. The creation of a bond with the pregnant women could prevent negative health outcomes for the child. In fact, in a study carried out in Kenya, knowledge of the diagnosis before prenatal care proved to be a protective factor against loss to follow-up (OR $0.23 ; 95 \% \mathrm{Cl}$ 0.05-0.71) [17]. A study conducted in the United States found that women diagnosed with HIV during pregnancy are less likely to receive ART adequately during pregnancy and to obtain viral suppression after pregnancy [56].

In our study, the variable moment of diagnosis was divided into two strata: diagnosis during prenatal care or at delivery and diagnosis before prenatal care. Therefore, because the women who may have been diagnosed during prenatal care were grouped with those diagnosed at delivery, we do not know the actual number of women who were diagnosed at childbirth. This is a limitation of our study and is an important issue to be discussed. Diagnosis at delivery may express the total absence of connection with primary care services or even the failure to perform an HIV test during prenatal care, a recommendation in force in a national protocol. A recent study discussed this issue in Brazil, showing that almost $20 \%$ of women in the state of Amazonas reached childbirth without knowing their HIV status, complementing another Brazilian study, in which $29 \%$ of women were not tested during prenatal care [57]. 
Like all scientific research, our study is not without limitations, the main one being that our study uses secondary databases, with the researcher having no control over the quality of data collected. However, we emphasize that we have used a database that is greatly valued by the surveillance team. In addition, the information was complemented by access to other health information systems. Therefore, we believe that this limitation has been reduced. Another limitation of the data already mentioned is the lack of HIV diagnosis during prenatal care or at delivery, which prevented us from identifying the percentage of women diagnosed at each of these care moments.

\section{Conclusion}

When considering the sociodemographic, behavioral, and health characteristics of the mothers, we found that the predictors of loss to follow-up refer to the individual, social and programmatic vulnerability in which these pregnant women and children live. We recommend investing in integrated health information systems so that children exposed to HIV can be located within the health care system, thus reducing the number of losses to follow-up. We also recommend a special focus on women using intravenous drugs, and the adoption of harm reduction actions, in order to avoid the loss of to follow-up of exposed children.

\section{Abbreviations}

ART: antiretroviral therapy; SINAN: Notifiable Diseases Information System; SISCEL: Laboratory Examination Control System; SICLOM: Logistic Control System for Medicines; E-SUS: electronic medical record of the primary care user; CADSUS: SUS User Registration System.

\section{Declarations}

\section{Ethics approval and consent to participate}

This study complied with the guidelines of the Resolution 466/2012 of the Brazilian National Health Council. The Ethics and Research Committee of the Federal University of Rio Grande do Sul (UFRGS) and the Ethics Committee of the Municipal Government of Porto Alegr approved the study, and waived the informed consent, due to the relevance of the study whose methodology used of a municipal secondary database with a large sample.

\section{Consent for publication}

Not applicable.

\section{Availability of data and material}

The datasets used and/or analyzed during the current study is available from the corresponding author upon reasonable request.

\section{Competing interests}


All authors declare that they have no competing interests.

\section{Funding}

Partial financial support was received form "Programa Pesquisa para o SUS (PPSUS/FAPERGS/MS/CNPq/SESRS n. 03/2017)".

\section{Authors' contributions}

LBT and DRK conceptualized the idea. All authors contributed to the study conception and design. Material preparation, data collection and analysis were performed by LBT and KSC. The first draft of the manuscript was written by KSC, LBT, BH and DRK. All authors commented on previous versions of the manuscript. All authors read and approved the final manuscript.

\section{Acknowledgements}

This research was supported by a Grant from Programa Pesquisa para o SUS PPSUS/FAPERGS/MS/CNPq/SESRS n. 03/2017.

\section{References}

1. UNAIDS. Joint United Nations Programme for HIV/AIDS. Start Free Stay Free AIDS Free: 2019 report. Geneva, Switzerland, 2019.

2. UNAIDS. Miles to go. Global AIDS update 2018. Geneva, 2018.

3. Ankunda R, Cumber SN, Atuhaire C, et al. Loss to follow-up and associated maternal factors among HIV-exposed infants at the Mbarara Regional Referral Hospital, Uganda: a retrospective study. BMC Infect Dis. 2020; 20 (235):1-9.

4. Vrazo AC, Sullivan D, Ryan Phelps B. Eliminating Mother-to-Child Transmission of HIV by 2030: 5 Strategies to Ensure Continued Progress. Glob Health Sci Pract. 2018; 6(2):249-56.

5. Yaya S, Oladimeji O, Oladimeji KE, Bishwajit G. Prenatal care and uptake of HIV testing among pregnant women in Gambia: a cross-sectional study. BMC Public Health. 2021; 20:485.

6. BRASIL. Ministério da Saúde. Boletim Epidemiológico Especial Secretaria de Vigilância em Saúde Ministério da Saúde. Boletim Epidemiológico de HIV e Aids. Brasília, 2020.

7. UNAIDS. Global AIDS Update, 2020. Seizing the moment - Tackling entrenched inequalities to end epidemics. Geneva, 2020.

8. Lockman S, Creek T. Acute Maternal HIV Infection during Pregnancy and Breast-Feeding: Substantial Risk to Infants. J Infec Dis. 2009; 200(5):667-9.

9. Saumu WM, Maleche-Obimbo E, Irimu G, Kumar R, Gichuhi C, Karau B. Predictors of loss to follow-up among children attending HIV clinic in a hospital in rural Kenya. Pan Afr Med J. 2019; 32(216):1-8.

10. Andrews M-M, Storm DS, Burr CK, et al. Perinatal HIV Service Coordination: Closing Gaps in the HIV Care Continuum for Pregnant Women and Eliminating Perinatal HIV Transmission in the United 
States. Public Health Rep. 2018; 133(5):532-42.

11. Office of AIDS Research Advisory Council, Panel on Treatment of Pregnant Women With HIV Infection and Prevention of Perinatal Transmission. Recommendations for the use of antiretroviral drugs in pregnant women with HIV infection and interventions to reduce perinatal HIV transmission in the United States. 2018.

12. UNAIDS. Global plan towards the elimination of new HIV infections among children by 2015 and keeping their mothers alive 2011-2015. Geneva, 2011.

13. Mohamed Y, Kupul M, Gare J, et al. Feasibility and acceptability of implementing early infant diagnosis of HIV in Papua New Guinea at the point of care: a qualitative exploration of health worker and key informant perspectives. BMJ Open. 2020; 10(11):e043679.

14. Kalawan V, Naidoo K, Archary M. Impact of routine birth early infant diagnosis on neonatal HIV treatment cascade in eThekwini district, South Africa. South Afr J HIV Med. 2020; 21(1).

15. Davies M-A, Pinto J. Targeting 90-90-90 - don't leave children and adolescents behind. J Int AIDS Soc. 2015; 18:20745.

16. Idele P, Hayashi C, Porth T, Mamahit A, Mahy M. Prevention of Mother-to-Child Transmission of HIV and Paediatric HIV Care and Treatment Monitoring: From Measuring Process to Impact and Elimination of Mother-to-Child Transmission of HIV. AIDS Behav. 2017; 21(1):23-33.

17. Kigen, Hudson Taabukk et al. Predictors of loss to follow up among HIV-exposed children within the prevention of mother to child transmission cascade, Kericho County, Kenya, 2016. Pan Afr Med J, v.30, n. 178, p. 1-10, jun 2018.

18. Frey MT, Meaney-Delman D, Bowen V, et al. Surveillance for Emerging Threats to Pregnant Women and Infants. J Womens Health. 2009; 28(8):1031-6.

19. Melo GC de, Oliveira ECA de, Leal IB, et al. Spatial and temporal analysis of the Human Immunodeficiency Virus (HIV) in an area of social vulnerability in Northeast Brazil. Geospat Health. 2020;15(2).

20. Mofenson LM, Cohn J, Sacks E. Challenges in the Early Infant HIV Diagnosis and Treatment Cascade. JAIDS. 2020; 84(1):S1-4.

21. BRASIL. Ministério da Saúde. Secretaria de Vigilância em Saúde. Coordenação Geral de Desenvolvimento da Epidemiologia em Serviços. Guia de Vigilância em Saúde. Brasília: Ministério da Saúde, 2019.

22. Mpinganjira S, Tchereni T, Gunda A, Mwapasa V. Factors associated with loss-to-follow-up of HIVpositive mothers and their infants enrolled in HIV care clinic: A qualitative study. BMC Public Health. 2020; 20(1):298.

23. Millar HC, Keter AK, Musick BS, et al. Decreasing incidence of pregnancy among HIV-positive adolescents in a large HIV treatment program in western Kenya between 2005 and 2017: a retrospective cohort study. Reprod Health. 2020; 17(1):191.

24. Chandiwana N, Sawry S, Chersich M, Kachingwe E, Makhathini B, Fairlie L. High loss to follow-up of children on antiretroviral treatment in a primary care HIV clinic in Johannesburg, South Africa. 
Medicine. 2018; 97(29):e10901.

25. Fisiha Kassa S, Zemene Worku W, Atalell KA, Agegnehu CD. Incidence of Loss to Follow-Up and Its Predictors Among Children with HIV on Antiretroviral Therapy at the University of Gondar Comprehensive Specialized Referral Hospital: A Retrospective Data Analysis. HIV AIDS (Auckl) . 2020; 12:525-33.

26. European Collaborative Study. CD4 Cell Response to Antiretroviral Therapy in Children with Vertically Acquired HIV Infection: Is It Associated with Age at Initiation? J Infect Dis. 2006;193(7):954-62.

27. Dang LVP, Pham VH, Nguyen DM, et al. Elevation of immunoglobulin levels is associated with treatment failure in HIV-infected children in Vietnam. HIV AIDS (AuckI). 2018; 11:1-7.

28. Guillén S, Prieto L, Jiménez de Ory S, et al. Prognostic factors of a lower CD4/CD8 ratio in long term viral suppression HIV infected children. PLoS One. 2019;14(8).

29. BRASIL. Ministério da Saúde. SINAN. Ficha de Notificação/Investigação. Criança exposta ao HIV, 2009.

30. Woldesenbet S, Jackson D, Lombard C, et al. Missed Opportunities along the Prevention of Mother-toChild Transmission Services Cascade in South Africa: Uptake, Determinants, and Attributable Risk (the SAPMTCTE). PLoS One. 2015; 10(7):e0132425

31. Harris K, Yudin MH. HIV Infection in Pregnant Women: A 2020 Update. Prenat Diagn. 2020; 40(13):1715-21.

32. Wexler C, Nazir N, Maloba M, et al. Programmatic evaluation of feasibility and efficiency of at birth and 6-week, point of care HIV testing in Kenyan infant. Nelson JA, organizador. PLoS One. 2020; 15(10):e0240621.

33. Sibanda E, Weller IVD, Hakim JG, Cowan FM. The magnitude of loss to follow-up of HIV-exposed infants along the prevention of mother-to-child HIV transmission continuum of care: a systematic review and meta-analysis. AIDS. 2013; 27(17):2787-97.

34. Wubneh CA, Belay GM, Yehualashet FA, Tebeje NB, Mekonnen BD, Endalamaw A. Lost to Follow-up and Predictors Among HIV-Exposed Infants in Northwest Ethiopia. Infect Dis Ther. 2020.

35. Kelly-Hanku A, Nightingale CE, Pham MD, et al. Loss to follow up of pregnant women with HIV and infant HIV outcomes in the prevention of maternal to child transmission of HIV programme in two high-burden provinces in Papua New Guinea: a retrospective clinical audit. BMJ Open. 2020; 10(12):e038311.

36. Mounier-Jack S, Mayhew SH, Mays N. Integrated care: learning between high-income, and low- and middle-income country health systems. Health Policy Plan. 2017; 32(suppl 4):iv6-iv12.

37. Haskins L, Chiliza J, Barker P, et al. Evaluation of the effectiveness of a quality improvement intervention to support integration of maternal, child and HIV care in primary health care facilities in South Africa. BMC Public Health. 2020; 20(3188):1-14.

38. BRASIL. Ministério da Saúde. Secretaria de Atenção à Saúde. Departamento de Atenção Básica. Caderno de Atenção Básica - Atenção ao pré-natal de baixo risco. 32. ed. Brasília: Ministério da Saúde, 2013. 
39. Hiarlaithe M, de Pee S, Bloem M. Economic and social factors are some of the most common barriers preventing women from accessing Maternal and Newborn Child Health (MNCH) and Prevention of Mother-to-Child Transmission (PMTCT) services: A literature review. AIDS Behav. 2014; 18(S5):516-30.

40. Alemu YM, Habtewold TD, Alemu SM. Mother's knowledge on prevention of mother-to-child transmission of HIV, Ethiopia: A cross sectional study. PLoS One. 2019; 13(9):e0203043.

41. Ayres JRCM, Calazans GJ, Saletti Filho HC, França Junior I. Risco, vulnerabilidade e práticas de prevenção e promoção da saúde. Tratado de Saúde Coletiva, São Paulo: 2009.

42. Kuhnt J, Vollmer S. Antenatal care services and its implications for vital and health outcomes of children: evidence from 193 surveys in 69 low-income and middle-income countries. BMJ Open. 2017; 7(11):e017122.

43. Warri D, George A. Perceptions of pregnant women of reasons for late initiation of antenatal care: a qualitative interview study. BMC Pregnancy Childbirth. 2020; 20(1):70.

44. Gonzalez A, Mimiaga MJ, Israel J, Andres Bedoya C, Safren SA. Substance Use Predictors of Poor Medication Adherence: The Role of Substance Use Coping Among HIV-Infected Patients in Opioid Dependence Treatment. AIDS Behav. 2017; 17(1):168-73.

45. Kerkerian G, Kestler M, Carter A, et al. Attrition Across the HIV Cascade of Care Among a Diverse Cohort of Women Living With HIV in Canada. JAIDS. 2018; 79(2):226-236.

46. Shokoohi M, Bauer GR, Kaida A. Patterns of social determinants of health associated with drug use among women living with HIV in Canada: a latent class analysis. Addiction. 2019; 114(7):1214-24.

47. BRASIL. Ministério da Saúde. Portaria $n^{\circ} 1.028$, de $1^{\circ}$ de julho de 2005. Determina que as ações que visem à redução de danos sociais e à saúde, decorrentes do uso de produtos, substâncias ou drogas que causem dependência, sejam reguladas por esta Portaria.

48. Ayon S, Jeneby F, Hamid F, Badhrus A, Abdulrahman T, Mburu G.

Developing integrated community-based HIV prevention, harm reduction, and sexual and reproductive health services for women who inject drugs. Reprod Health. 2019; 16(Suppl 1):59.

49. Samoff E, Mobley V, Hudgins M, et al. HIV Outbreak Control With Effective Access to Care and Harm Reduction in North Carolina, 2017-2018. Am J Public Health. 2020; 110(3):394-400.

50. Freeman R, Gwadz MV, Silverman E, et al. Critical race theory as a tool for understanding poor engagement along the HIV care continuum among African American/Black and Hispanic persons living with HIV in the United States: a qualitative exploration. Int J Equity in Health. 2017; 16(54):1-14, 2017.

51. Trent M, Dooley DG, Dougé J, Section on Adolescent Health, Council on Community Pediatrics and Committee on Adolescence. The impact of racism on child and adolescent health. Pediatrics. 2019; 144(2):e20191765.

52. Aungsataporn S, Phaloprakarn C, Tangjitgamol S. Characteristics associated with loss to postpartum follow-up among adolescent mothers. J Obstet Gynaecol Res. 2019;45(5):981-986. 
53. Ejigu Y, Tadesse B. HIV testing during pregnancy for prevention of mother-to-child transmission of HIV in Ethiopia. PLoS One 2018; 13(8):1-11.

54. Cesar JA, Black RE, Buffarini R. Antenatal care in Southern Brazil: Coverage, trends and inequalities. Prev Med. 2021; 145:106432.

55. Trindade LMM, Nogueira LMV, Rodrigues ILA, Ferreira AMR, Corrêa GM, Andrade NCO. HIV infection in pregnant women and its challenges for the prenatal care. Rev Bras Enferm. 2021; 74(suppl 4):e20190784.

56. Monplaisir FM, Brady KA, Fekete T, Thompson DR, Roux AD, Yehia BR. Time of HIV diagnosis and engagement in prenatal care impact virologic outcomes of pregnant women with HIV. PLoS One 2015; 10 (7):e0132262.

57. Miranda AE,Pereira GFM, Araujo MAL, et al. Avaliação da cascata de cuidado na prevenção da transmissão vertical do HIV no Brasil. Cad. Saúde Pública 2016; 32(9):1-10. 